University of Wollongong

Research Online

Faculty of Engineering - Papers (Archive)

Faculty of Engineering and Information

Sciences

$1-1-2009$

\title{
First-principles study on the enhancement of lithium storage capacity in boron doped graphene
}

Xianlong Wang

University of Wollongong, xianlong@uow.edu.au

Zhi Zeng

Chinese Academy of Sciences

HyoJun Ahn

Gyeongsang National University Republic of Korea

Guoxiu Wang

University of Wollongong, gwang@uow.edu.au

Follow this and additional works at: https://ro.uow.edu.au/engpapers

Part of the Engineering Commons

https://ro.uow.edu.au/engpapers/2665

\section{Recommended Citation}

Wang, Xianlong; Zeng, Zhi; Ahn, HyoJun; and Wang, Guoxiu: First-principles study on the enhancement of lithium storage capacity in boron doped graphene 2009, 1-3.

https://ro.uow.edu.au/engpapers/2665

Research Online is the open access institutional repository for the University of Wollongong. For further information contact the UOW Library: research-pubs@uow.edu.au 


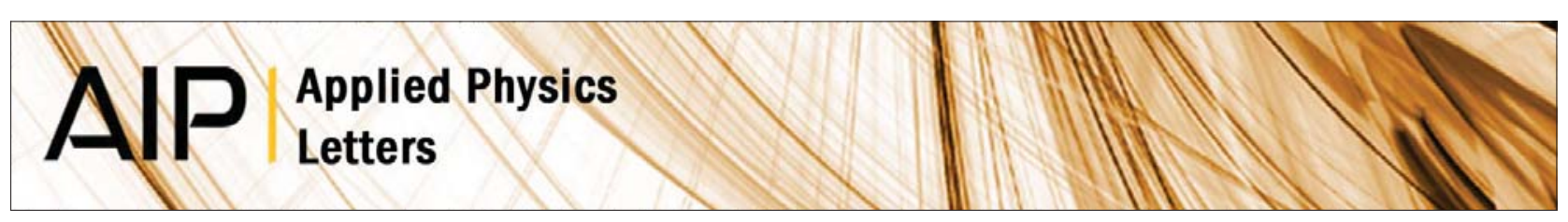

\section{First-principles study on the enhancement of lithium storage capacity in boron doped graphene}

Xianlong Wang, Zhi Zeng, Hyojun Ahn, and Guoxiu Wang

Citation: Appl. Phys. Lett. 95, 183103 (2009); doi: 10.1063/1.3259650

View online: http://dx.doi.org/10.1063/1.3259650

View Table of Contents: http://apl.aip.org/resource/1/APPLAB/v95/i18

Published by the American Institute of Physics.

\section{Related Articles}

Structure, magnetism, and magnetic compensation behavior of Co50-xMn25Ga25+x and Co50-xMn25+xGa25

Heusler alloys

J. Appl. Phys. 113, 103903 (2013)

Oxygen segregation at coherent grain boundaries of cubic boron nitride

Appl. Phys. Lett. 102, 091607 (2013)

Lead incorporation mechanism in LiF crystals

Appl. Phys. Lett. 102, 081107 (2013)

Validation of density functionals for transition metals and intermetallics using data from quantitative electron diffraction

J. Chem. Phys. 138, 084504 (2013)

Low-bias electron transport properties of germanium telluride ultrathin films

J. Appl. Phys. 113, 063711 (2013)

\section{Additional information on Appl. Phys. Lett.}

Journal Homepage: http://apl.aip.org/

Journal Information: http://apl.aip.org/about/about_the_journal

Top downloads: http://apl.aip.org/features/most_downloaded

Information for Authors: http://apl.aip.org/authors

\section{ADVERTISEMENT}

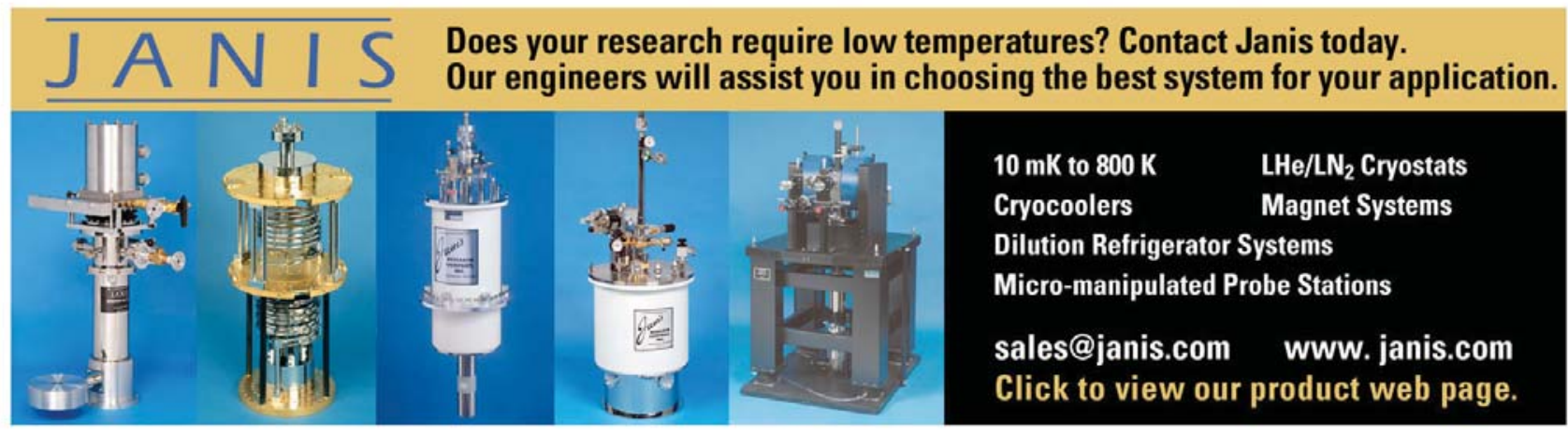




\title{
First-principles study on the enhancement of lithium storage capacity in boron doped graphene
}

\author{
Xianlong Wang, ${ }^{1,2}$ Zhi Zeng, ${ }^{2}$ Hyojun Ahn, ${ }^{3}$ and Guoxiu Wang ${ }^{1, a)}$ \\ ${ }^{1}$ School of Mechanical, Materials and Mechatronic Engineering and Institute for Superconducting and \\ Electronic Materials, University of Wollongong, New South Wales 2522, Australia \\ ${ }^{2}$ Key Laboratory of Materials Physics, Institute of Solid State Physics, Chinese Academy of Sciences, \\ Hefei 230031, People's Republic of China \\ ${ }^{3}$ School of Materials Science and Engineering, Gyeongsang National University, 900 Gazwa-dong, Jinju, \\ Gyeongnam 660-701, Republic of Korea
}

(Received 21 August 2009; accepted 19 October 2009; published online 4 November 2009)

\begin{abstract}
The adsorption of Li ions on boron doped graphene was investigated using a first-principles method. Our results show that, as boron doping turns graphene into an electron-deficient system, more Li ions can be captured around boron doped centers than in pristine graphene. One boron atom doped into graphene (6C ring unit) can adsorb six Li ions, which indicates that boron doped graphene is an efficient Li-ion storage material for lithium batteries. Further investigations show that, under limited conditions, boron doped graphene $\left(\mathrm{BC}_{5}\right)$ can form $\mathrm{Li}_{6} \mathrm{BC}_{5}$ compound after $\mathrm{Li}$-ion adsorption, corresponding to a lithium storage capacity of $2271 \mathrm{mAh} / \mathrm{g}$ which is six times that of graphite. (C) 2009 American Institute of Physics. [doi:10.1063/1.3259650]
\end{abstract}

Lithium ion batteries are the state-of-the art power sources for portable electronic devices and potentially for electric vehicles and hybrid electric vehicles. They use the chemistry of lithium transition metal oxide cathode and graphite anode. ${ }^{1,2}$ However, graphite is not an ideal anode material for lithium ion batteries due to its limited lithium storage capacity $(372 \mathrm{mAh} / \mathrm{g})$. Carbon nanotubes (CNTs) have been studied for use as high capacity lithium storage materials because CNTs can adsorb Li ions both on the outside and on the inside surfaces. Experimental investigations have shown that single-wall CNTs exhibit a reversible capacity of upto $500 \mathrm{mAh} / \mathrm{g},{ }^{3}$ significantly higher than that of graphite. The maximum capacity of CNTs can be increased to as high as $1000 \mathrm{mAh} / \mathrm{g}$ (in the form of $\mathrm{Li}_{2.7} \mathrm{C}_{6}$ ) by chemical etching ${ }^{4}$ or ball-milling, ${ }^{5}$ which open up paths allowing $\mathrm{Li}$ ions to diffuse inside the CNTs. Ever since boron doped CNTs with different $\mathrm{B}$ versus $\mathrm{C}$ ratios have been synthesized, ${ }^{6-8}$ they have been expected to have higher Liion storage capability than pristine CNTs, and this has been confirmed both experimentally ${ }^{9}$ and theoretically. ${ }^{10}$ Additionally, boron doped carbonaceous materials have exhibited higher reversible capacity and better cycling stability than their pure counterparts. ${ }^{11,12}$

Recently, graphene or graphite in single-layer form, has attracted tremendous attention because of its excellent structural and electronic properties, such as chemical and thermal stability, high electrical conductivity, and mechanical strength. ${ }^{13,14}$ Graphene is a strictly two-dimensional, flat, and single-layer material. Unlike CNTs, graphene has two equal surfaces. Very recently, the Li ions storage capacity of graphene was found to be $784 \mathrm{mAh} / \mathrm{g},{ }^{15}$ which is twice the capacity of graphite. The reason may be that graphene adsorbs $\mathrm{Li}$ ions on its two equal surfaces, forming $\mathrm{LiC}_{3}$ compound. As mentioned above, the Li ion storage capacity can be enhanced by doping boron into both graphite and CNTs.

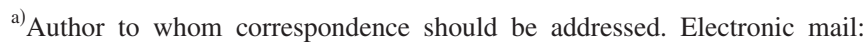
gwang@uow.edu.au.
}

In this letter, we dope boron into graphene to investigate the enhancement of Li-ion storage by inspecting the electronic structures of boron doped graphene and its $\mathrm{Li}$ ion storage capacity.

Density functional theory (DFT), as implemented in the $\mathrm{Dmol}^{3}$ package $^{16}$ is used in our electronic structure calculations. The parameterization by Perdew, Burke, and Ernzerhof ${ }^{17}$ is used for exchange and correlation interaction in the generalized gradient approximation. A double numerical basis set and a polarized function were chosen for calculations. A supercell $(2 \sqrt{3} \times 2 \sqrt{3}) R 30^{\circ}$ containing 24 atoms $\left(S C_{1}\right)$ is used to investigate the interaction of the Li ions with a single boron doped defect. There are one boron and 23 carbon atoms in one boron doped $S C_{1}$, termed $\mathrm{BC}_{23}$, in which the boron concentration is 4.17 at. \%. The Brillouin zone of $S C_{1}$ is sampled by a $4 \times 4 \times 1$ Monkhorst and Pack grid. ${ }^{18}$ The interaction between the $\mathrm{Li}$ ions and the 16.7 at. $\%$ boron doped graphene, corresponding to $\mathrm{BC}_{5}$ compound, is modeled in a $(\sqrt{3} \times \sqrt{3}) R 30^{\circ}$ supercell containing six atoms $\left(S C_{2}\right)$. The reciprocal space of this supercell is represented by an $8 \times 8 \times 1$ Monkhorst and Pack grid. The $z$-direction lattice constant is fixed at $20 \AA$. All structures are fully relaxed until the force is less than $0.054 \mathrm{eV} / \AA$.

The optimized in-plane lattice constant of pristine graphene is $2.463 \AA$, which is close to the experimental value of $2.460 \AA$. The relaxed lattice constant of boron doped graphene is 2.484 or $2.536 \AA$, corresponding to the concentration of 4.17 or 16.7 at. \%, respectively. Because the boron covalent radius is larger than that of its carbon counterpart, the lattice constant of doped graphene increases with increasing boron concentration. The average adsorption energy per $\mathrm{Li}$ ion $\left(E_{a d}\right)$ is defined as follows:

$$
E_{a d}=\left(E_{g r a}+n E_{L i}-E_{L i-g r a}\right) / n,
$$

where $E_{L i}, E_{\text {gra }}$, and $E_{L i-g r a}$ represent the total energy of a lithium atom, the pristine graphene, and the Li-graphene, respectively. $n$ is the number of $\mathrm{Li}$ ions. 

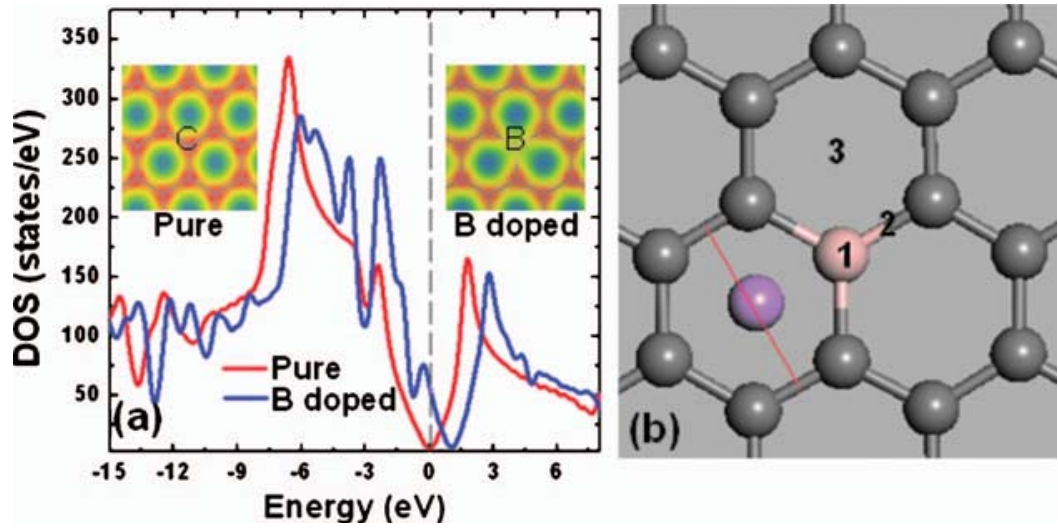

FIG. 1. (Color) (a) The DOS of pristine and boron doped graphene. (b) A schematic map showing one Li ion adsorbed on boron doped graphene. The red line indicates the hexagon center, and 1, 2, and 3 represent the three high symmetry sites: the top, bridge, and hollow, respectively. Contour plots of the electron density along the graphene plane for pristine and boron doped graphene are shown in the left and right insets of (a), respectively.
First, the electronic properties of pristine and boron doped graphene were investigated using $S C_{1}$. As shown in Fig. 1(a), after boron doping, as boron has one electron less than carbon, the Fermi level is depressed into the valence band, and the graphene becomes an electron-deficient system. The contour plots of the electron density of pristine and boron doped graphene are shown in the insets of Fig. 1(a). The graphics imply that the electron-deficient area of boron doped graphene is mainly distributed around the boron. Boron substitution may increase the electronic conductivity and $\mathrm{Li}$ ion adsorption of graphene.

As in pristine graphene, there are three high symmetry positions for Li ions adsorbed on boron doped graphene. As shown in Fig. 1(b), they are the top site (above the boron atom), the bridge site (above the bond center of the B-C bond), and the hollow site (above the center of the hexagon), respectively. ${ }^{19}$ After full relaxation, our calculated results show that the hollow site is the most favored site with the minimum total energy, while the top and the bridge sites are the second and third most stable positions. Also, we should note that the hollow site is the most stable site for Li ions in CNTs and pristine graphene as well. ${ }^{10,20-23}$ The final position of a single adsorbed Li ion is shown in Fig. 1(b), where it should be noted that the Li ion deviates slightly from the center of the hexagon and comes closer to the boron. After introducing boron into pristine graphene, the original symmetry is broken. Because boron atoms and Li ions are electron acceptors and donors, respectively, the Li ions and boron tend to attract each other.

We further investigated the case of the adsorption of two Li ions, as shown in Fig. 2. $A, B$, and $C$ are used to represent the three nearest hollow sites around the boron. Up and down mark the upper and lower sides of the graphene. Using those signs, the position of one $\mathrm{Li}$ ion is well defined, for example, $A_{\text {up }}$ corresponds to the configuration of one Li ion located on the top of the $A$ site on the upper side. As mentioned above, $\mathrm{Li}$ ions prefer to be situated on the top of the hexagon center, and therefore, $A_{\text {up }}-B_{\text {up }}, A_{\text {up }}-A_{\text {down }}$, and $A_{\text {up }}-B_{\text {down }}$ are used for simulating the adsorption of two Li ions. From $A_{\text {up }}-B_{\text {up }}$ to $A_{\text {up }}-B_{\text {down }}$, the distance between Li ions increases gradually. The relaxed configurations and distances between two $\mathrm{Li}$ ions are shown in Figs. 2(a)-2(c), which indicates that the total energy decreases monotonically with increasing $\mathrm{Li}-\mathrm{Li}$ distance. This fact tells us that Li ions tend to separate themselves as far as possible from each other around boron. In this way, additional Li ions are put around a nearby boron atom until the extreme case shown in Fig. 2(d), in which six $\mathrm{Li}$ ions are adsorbed around boron. After the Li ions are adsorbed on boron doped graphene, Li ions transfer electrons to the host material. As shown in Fig. 3(a), the average net charge and adsorption energy of a Li ion decrease with increasing number of Li ions, which mean that the ability of doped graphene to adsorb Li ions is progressively weakened [Eq. (1)]. However, in the case of the adsorption of six $\mathrm{Li}$ ions, the average adsorption energy is as high as $1.976 \mathrm{eV}$, which indicates that one boron doped center can capture six Li ions. Density of states (DOS) analysis for the case where six Li ions are adsorbed [see Fig. 3(b)], shows that Li ion adsorption can raise the Fermi level of the graphene. As can be seen in Fig. 3(c), the contribution of Li ions to the total DOS around the Fermi level is from both $s$ and $p$ orbitals. It should be noted that the current boron concentration is 4.167 at. $\%$.

Next, we increase the boron concentration to 16.7 at. \%, corresponding to $\mathrm{BC}_{5}$ compound, in which each hexagon has a boron neighbor. As discussed above, one boron can adsorb six $\mathrm{Li}$ ions in $\mathrm{BC}_{23}$. However, can each hexagon accommodate two $\mathrm{Li}$ ions in $\mathrm{BC}_{5}$ ? $\mathrm{Six} \mathrm{Li}$ ions were put into $\mathrm{SC}_{2}$, forming $\mathrm{Li}_{6} \mathrm{BC}_{5}$ compound. The calculated results are given in Table I. The distance between the $\mathrm{Li}$ ion and the graphene



FIG. 2. (Color) Schematic map of two Li ions adsorbed on boron doped graphene: (a), (b), and (c) illustrate the $A_{\text {up }}-B_{\text {up }}, A_{\text {up }}-A_{\text {down }}$ and $A_{\text {up }}-B_{\text {down }}$ configurations, respectively. The numbers show the distance between the two Li ions. (d) The structure for adsorption of six Li ions. The purple and yellow balls represent $\mathrm{Li}$ ions located at up and down sites, respectively. The pink balls represent sites occupied by boron. 

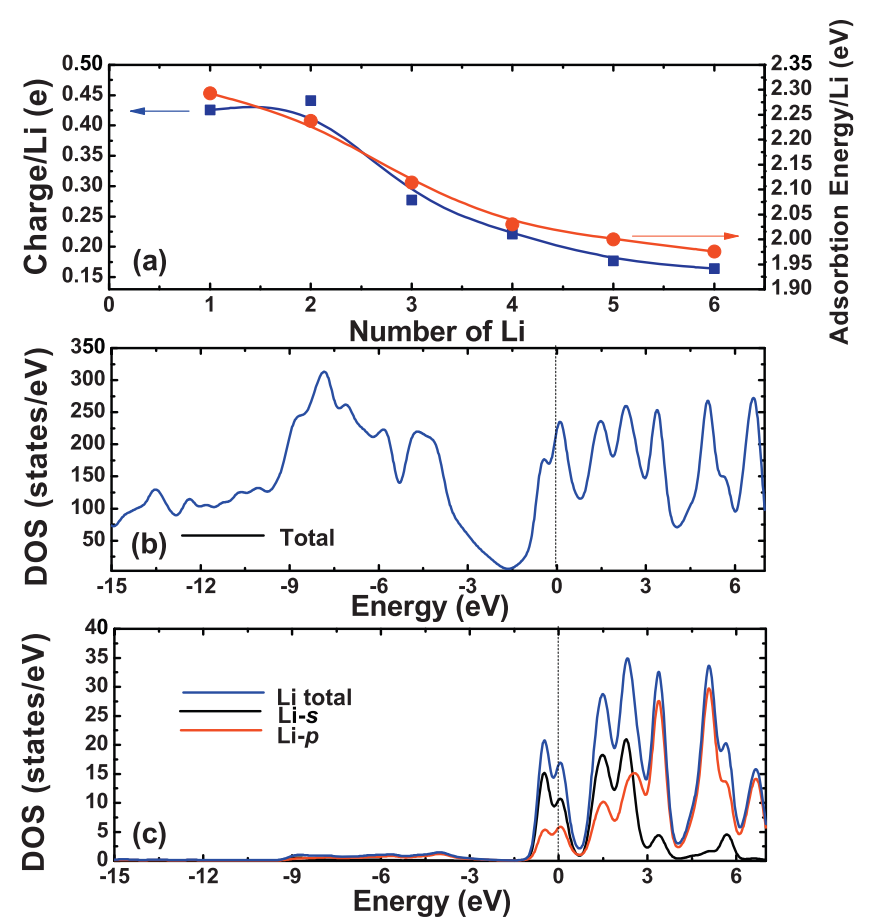

FIG. 3. (Color) (a) Average charge and adsorption energy of Li ion vs number of $\mathrm{Li}$ ions, (b) the total DOS of the case where six $\mathrm{Li}$ ions are adsorbed, and (c) the corresponding total, and the $\mathrm{p}$ and $\mathrm{s}$ contributions to the DOS from Li ions.

is $1.925 \AA$, and the average absorption energy is $0.759 \mathrm{eV}$. As there are two even $\mathrm{Li}$ layers in $\mathrm{Li}_{6} \mathrm{BC}_{5}$ and the $\mathrm{Li}-\mathrm{Li}$ distance is $2.543 \AA$, hence, the calculated adsorption energy comes from the two following parts: one is the interaction between the $\mathrm{Li}$ ions and the graphene and the other is from the interaction among Li ions. In order to obtain the pure adsorption energy of $\mathrm{Li}$ ions on graphene, the graphene layer is removed from the $\mathrm{Li}_{6} \mathrm{BC}_{5}$ compound, and the bonding energy between the $\mathrm{Li}$ ions among Li layers is found to be $0.454 \mathrm{eV}$. Therefore, the pure average adsorption energy of $\mathrm{Li}$ ions on graphene is $0.305 \mathrm{eV}$, indicating that $\mathrm{Li}_{6} \mathrm{BC}_{5}$ compound can exist stably. Simultaneously, we did the calculations for the pristine graphene $\mathrm{Li}_{6} \mathrm{C}_{6}$ compound for a comparison, and the calculated results are shown in Table I. There is almost no

TABLE I. The relaxed Li-graphene distance, the average net charge, and adsorption energy of $\mathrm{Li}$ ions in $\mathrm{Li}_{6} \mathrm{C}_{6}$ and $\mathrm{Li}_{6} \mathrm{BC}_{5}$ compounds, respectively. The pure adsorption energy between $\mathrm{Li}$ ions and the host is shown in parentheses.

\begin{tabular}{lccc}
\hline \hline \multicolumn{1}{c}{ Composition } & $\begin{array}{c}\mathrm{D}_{\mathrm{Li}-\text { graphene }}(\AA) \\
\mathrm{Li}_{6} \mathrm{BC}_{5}\end{array}$ & $\begin{array}{c}\text { Li charge } \\
(\mathrm{e})\end{array}$ & $\begin{array}{c}\text { Adsorption energy } \\
(\mathrm{eV})\end{array}$ \\
$\mathrm{Li}_{6} \mathrm{C}_{6}$ & 1.925 & 0.066 & $0.759(0.305)$ \\
\hline \hline
\end{tabular}

interaction between $\mathrm{Li}$ ions and graphene in $\mathrm{Li}_{6} \mathrm{C}_{6}$, implying that $\mathrm{Li}_{6} \mathrm{C}_{6}$ compound cannot exist stably.

In summary, the adsorption of $\mathrm{Li}$ ions on boron doped graphene has been investigated using DFT calculations. After boron doping, graphene becomes an electron-deficient system, and an electron-deficient center appears around each boron atom. Li ions tend to situate themselves on the top of hexagon centers with a boron neighbor. Our calculations indicate that the $\mathrm{Li}$ ion storage capacity can be dramatically improved to $2271 \mathrm{mAh} / \mathrm{g}$ by boron doping and that $\mathrm{Li}_{6} \mathrm{BC}_{5}$ can exist stably.

We gratefully acknowledge the financial support from the Australian Research Council (ARC) through the ARC Discover Project No. DP0772999 and the National Research Foundation of Korea through the WCU (World Class University) Program No. R32-2008-000-20093-0.

${ }^{1}$ J. R. Dahn, T. Zheng, Y. Liu, and J. S. Xue, Science 270, 590 (1995).

${ }^{2}$ J. M. Tarascon and M. Armand, Nature (London) 414, 359 (2001).

${ }^{3}$ A. S. Claye, J. E. Fischer, C. B. Huffman, A. G. Rinzler, R. E. Smalley, and J. Electrochem. Soc 147, 2845 (2000).

${ }^{4}$ H. Shimoda, B. Gao, X. P. Tang, A. Kleinhammes, L. Fleming, Y. Wu, and O. Zhou, Phys. Rev. Lett. 88, 015502 (2002).

${ }^{5}$ B. Gao, C. Bower, J. D. Lorentzen, L. Fleming, A. Kleinhammes, X. P. Tang, L. E. Mc-Neil, Y. Wu, and O. Zhou, Chem. Phys. Lett. 327, 69 (2000).

${ }^{6}$ W. Han, Y. Bando, K. Kurashima, and T. Sato, Appl. Phys. Lett. 73, 3085 (1998).

${ }^{7}$ D. Golberg, Y. Bando, L. Bourgeois, K. Kurashima and T. Sato, Carbon 38, 2017 (2000).

${ }^{8}$ P. L. Gai, O. Stephan, K. M. Guire, A. M. Rao, M. S. Dresselhaus, G. Dresselhaus, and C. Colliex, J. Mater. Chem. 14, 669 (2004).

${ }^{9}$ I. Mukhopadhyay, N. Hoshino, S. Kawasaki, F. Okino, W. K. Hsu, and H. Touhara, J. Electrochem. Soc. 149, A39 (2002).

${ }^{10}$ Z. Zhou, J. J. Zhou, Z. P. Gao, Z. F. Chen, J. Yan, P. V. R. Schleyer, and M. Morinaga, Chem. Mater. 17, 992 (2005).

${ }^{11}$ B. M. Way and J. R. Dahn, J. Electrochem. Soc. 141, 907 (1994).

${ }^{12}$ M. Endo, C. Kim, T. Karaki, Y. Nishimura, M. J. Matthews, S. D. M. Brown, and M. S. Dres-selhaus, Carbon 37, 561 (1999).

${ }^{13}$ K. S. Novoselov, A. K. Geim, S. V. Morozov, D. Jiang, Y. Zhang, S. V. Dubonos, I. V. Grigorieva, and A. A. Firsov, Science 306, 666 (2004).

${ }^{14}$ A. K. Geim and K. S. Novoselov, Nature Mater. 6, 183 (2007).

${ }^{15}$ E. J. Yoo, J. Kim, E. Hosono, H. S. Zhou, T. Kudu, and I. Honma, Nano Lett. 8, 2277 (2008)

${ }^{16}$ R. S. Mulliken, J. Chem. Phys. 23, 1841 (1955).

${ }^{17}$ J. P. Perdew, K. Burke, and M. Ernzerhof, Phys. Rev. Lett. 77, 3865 (1996).

${ }^{18}$ H. J. Monkhorst and J. D. Pack, Phys. Rev. B 13, 5188 (1976).

${ }^{19}$ K. T. Chan, J. B. Neaton, and M. L. Cohen, Phys. Rev. B 77, 235430 (2008).

${ }^{20}$ M. Khantha, N. A. Cordero, L. M. Molina, J. A. Alonso, and L. A. Girifalco, Phys. Rev. B 70, 125422 (2004).

${ }^{21}$ M. Khantha, N. A. Cordero, J. A. Alonso, M. Molina, and L. A. Girifalco, Phys. Rev. B 78, 115430 (2008).

${ }^{22}$ L. Chen, Y. M. Zhang, N. Koratkar, P. Jena, and S. K. Nayak, Phys. Rev. B 77, 033405 (2008).

${ }^{23}$ M. Farjam and H. Rafii-Tabar, Phys. Rev. B 79, 045417 (2009). 